\title{
Cincuenta años (1956-2006) de crecimiento urbano y degradación de suelos por sellado antropogénico en el término municipal de Valencia
}

\author{
Antonio Valera Lozano \\ antonio.valera@uv.es \\ Carlos AÑó VIDAL \\ carlos.anyo@uv.es \\ Juan SÁnchez DíAZ \\ juan.sanchez@uv.es \\ Departamento de Planificación Territorial. CIDE \\ (CSIC-Universitat de València-Generalitat Valenciana).
}

Recibido: 4 de Noviembre de 2010

Enviado a evaluar: 2 de Marzo de 2011

Aceptado: 28 de Junio de 2011

\section{RESUMEN}

En este trabajo se analiza la dinámica espacio-temporal de los usos urbanos durante la segunda mitad del siglo XX en el municipio de Valencia. A partir de fotogramas aéreos correspondientes a las fechas de 1956, 1984 y 2006 y mediante métodos de análisis cartográficos con Sistemas de Información Geográfica, se han establecido los cambios acumulativos de los usos urbanos del suelo aplicando un sistema de indicadores. Los resultados muestran la gran expansión de los usos urbanos y el consecuente retroceso de los agrícolas y forestales durante todo el periodo analizado. La superficie construida, que representaba 2.007 ha $(14,85 \%$ del municipio) en 1956, alcanza 4.385 ha $(32,67 \%)$ en 2006 . El área dedicada a los usos urbanos del suelo se ha duplicado en 50 años y representa más de un tercio del municipio en la actualidad. Además, gran parte del crecimiento se ha producido sobre suelos con elevada y muy elevada capacidad de uso.

Palabras clave: Urbanización, dinámica espacio-temporal, sellado antropogénico, áreas litorales mediterráneas 


\title{
Urban growth (1956-2006) and soil degradation by soil sealing in the municipality of Valencia
}

\begin{abstract}
This paper analyses the spatial and temporal dynamics of the urban uses during the second half of the 20th century in the municipality of Valencia, which is located in the Valencia metropolitan area. Changes in urban uses were established by using the aerial photographs dated in 1956, 1984 and 2006 and map analysis based on Geographical Information Systems. The results show an importance in the process of urban growth from 1956 to 2006 and a reduction of the agricultural and forest uses. Whereas in 1956 the built-up areas represented 2,007 ha (15\% of the total area), in 2006 the surface occupied by urban use was 4,385 ha $(33 \%)$. One third part of the municipality has been built-up in fifty years, mainly on prime farmlands.
\end{abstract}

Key words: Urbanization, spatial and temporal dynamic, soil sealing, Mediterranean coastal areas.

\section{Croissance urbaine (1956-2006) et dégradation du sol per scellé artificiel dans la municipalité du Valencia}

\section{RÉSUMÉ}

Cet article a pour objet l'analyse de la dynamique spatiale et temporale des utilisations urbaines durant la deuxième moitié du vingtième siècle dans la municipalité de Valencia, qui se localise dans le milieu métropolitain de Valencia. A partir des photogrammes aériens qui correspondent aux dates suivantes: 1956, 1984 et 2006 et moyennant les méthodes d'analyses cartographiques et l'utilisation du Système d'Information Géographique, il a été établi les changements cumulatifs des utilisations urbaines du sol. Les résultats obtenus montrent l'importance de la croissance urbaine pendant la période d' étude, spécialement le pourcentage élevée de la surface municipale destinée à cette utilisation à l'issue de l'étude. En 1956, date d'initiation de l'analyse, l'utilisation urbaine a représenté 2.007 (15\% de la surface totale). Cinquante ans après, l'utilisation urbaine a représenté 4.385 ha (33\%), et la majorité du la croissance se produire sur les sols plus productives.

Mots clef: Croissance urbaine, dynamique spatiale et temporales, scellé artificiel du sol, côte méditerranéenne.

\section{INTRODUCCIÓN}

Dentro de los importantes cambios experimentados por los usos y cubiertas del suelo durante los últimos 50 años, el espectacular crecimiento experimentado por las superficies artificiales es, sin duda, el más remarcable por reflejar sobre el territorio, en un corto periodo de tiempo, las dinámicas socioeconómicas y, además, por su influencia en la transformación de otros usos. La expansión de las superficies construidas puede tener importantes repercusiones sobre el medio ambiente (NUISSL et al., 2009; MARM, 2009), especialmente sobre el recurso edáfico. Entre los diversos y complejos procesos que pueden intervenir en la degradación del edafosistema uno de los más importantes, aunque poco estudiado, es la pérdida del recurso producida por el proceso denominado genéricamente soil sealing en la literatura anglosajona y 
que puede definirse como el sellado antropogénico del suelo con superficies duras e impermeables ocasionado por la urbanización, la industrialización o la implantación de infraestructuras (EEA, 2002). SCALENGHE y AJMONE-MARSAN (2009) recogen los principales impactos negativos que este proceso tiene sobre algunas de las funciones del suelo: en las transferencias de energía, los movimientos de agua, la difusión de gases y la biota.

A escala europea, no obstante, existe una significativa carencia de datos detallados de la relevancia espacial del fenómeno y del tipo de suelos que se están viendo afectados, una información fundamental en el análisis del proceso (CEC, 2002). En la Unión Europea el sellado antropogénico es la principal causa de degradación del suelo en los países más industrializados y poblados de oeste y norte de Europa, y su relevancia se está incrementando alarmantemente en otros países, entre ellos, Portugal y España (EEA, 2006a). El litoral español ha asistido, durante las últimas décadas, al retroceso de los usos agrícolas y forestales tradicionales ante la expansión de las superficies urbanas (OJEDA y VILLAR, 2006; ACOSTA et al., 2007; VALERA et al., 2007a). El proceso ha tenido especial relevancia en los centros metropolitanos, que concentran la mayor parte de la población, las actividades económicas, y las principales infraestructuras y equipamientos (SERRANO, 2005). Pero no se trata sólo del incremento de la población, sino que también puede ser resultado de un cambio de comportamiento de la sociedad en la utilización del territorio (EEA, 2006b).

La gran mayoría de los trabajos que abordan el estudio de la dinámica de usos y coberturas del suelo, y especialmente los que se centran en la evolución de los usos urbanos, utilizan como información de partida datos procedentes de imágenes de percepción remota, ya sean fotografías aéreas o imágenes de satélite, aprovechando las potencialidades de los Sistemas de Información Geográfica - SIG (TREITZ y ROGAN, 2004). La conjunción de estas técnicas, permite obtener información fácilmente actualizable del fenómeno estudiado y con gran precisión espacial. Así, a partir de una cartografía detallada sobre usos del suelo, el proyecto MOLAND (Monitoring Land Use Changes) utiliza indicadores en el análisis de las dinámicas y desarrollo regional y urbano de sus áreas de estudio. En ese proyecto, KASANKO et al. (2006) aplicaron un conjunto de indicadores para analizar el estado y tendencia de los usos urbanos del suelo y de la población en 15 ciudades europeas durante los últimos 50 años, no encontrándose entre ellas ninguna del litoral mediterráneo español. En el trabajo que se desarrolla a continuación se analiza la dinámica espaciotemporal de los usos urbanos, y la consiguiente pérdida del recurso edáfico, durante la segunda mitad del siglo XX y primer lustro del siglo XXI en Valencia.

\section{MATERIALES Y MÉTODOS}

El área de estudio está constituida por el municipio de Valencia, localizado en el litoral mediterráneo español, aproximadamente en los $39^{\circ} 28^{\prime} 36^{\prime \prime}$ de latitud Norte y $0^{\circ} 22^{\prime} 28^{\prime}$ " de longitud Oeste (Figura 1). La superficie total (excluyendo el área de expansión portuaria desde 1956) es de 13.422 ha. El municipio acoge la ciudad 
Figura 1: Localización del área de estudio.

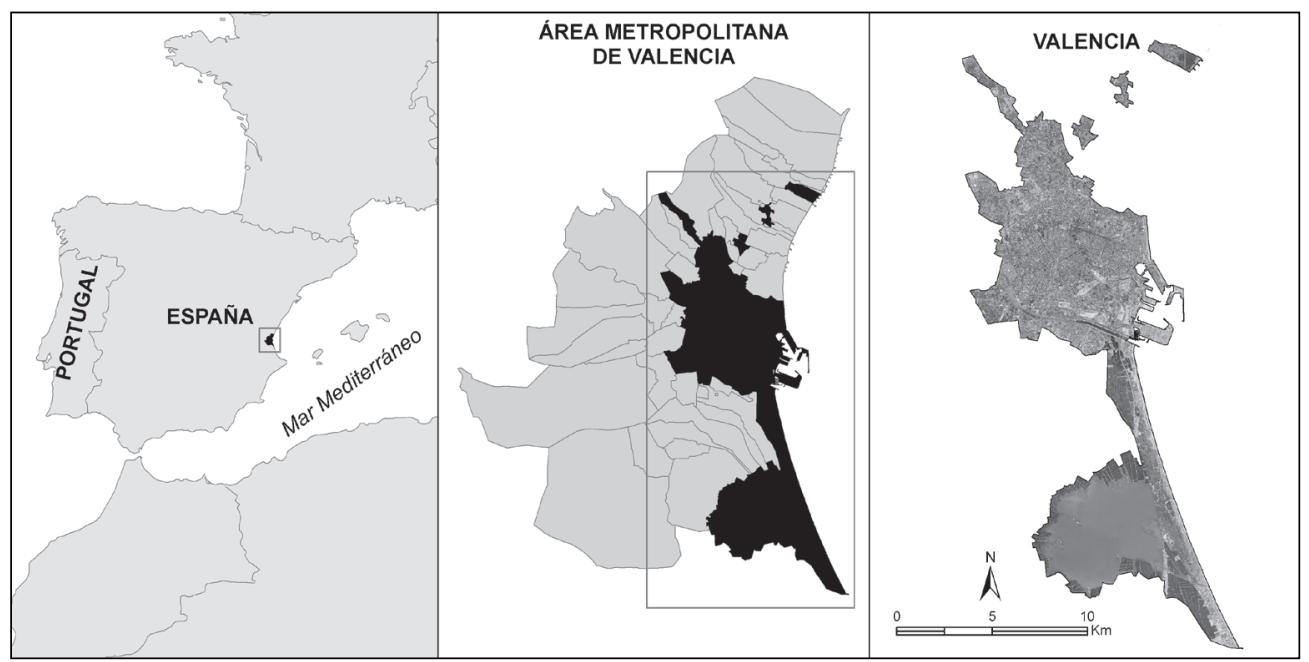

Fuente: Elaboración propia

de Valencia, que es, al mismo tiempo, capital regional y ciudad central de un área metropolitana de más de 1,5 millones de habitantes en 2009.

A partir de imágenes correspondientes a las fechas de 1956, 1984 y 2006, y utilizando métodos de análisis cartográfico con SIG, se han obtenido los cambios acumulativos de los usos del suelo a escala detallada (1:10.000) según el procedimiento que se esquematiza en la figura 2. Los fotogramas de los vuelos de 1956 (Servicio Geográfico del Ejército) y 1984 (Instituto Geográfico Nacional) fueron escaneados a alta resolución y ortorrectificados, identificando puntos de control sobre una ortofoto actual (2006) realizada por el Instituto Cartográfico Valenciano (ICV) y un modelo digital de elevaciones. Se obtuvieron así ortofotografías digitales georreferenciadas y sin deformaciones (SÁNCHEZ-ESPESO, 2000). El mapa topográfico digital, escala 1:10.000, del ICV constituyó la base de referencia cartográfica para la incorporación de la información aportada por las imágenes de 1956, 1984 y 2006. La metodología está diseñada para incorporar otras fechas, permitiendo, de este modo, la actualización constante y progresiva. A partir de esas imágenes en formato ráster se realizó, mediante técnicas convencionales de fotointerpretación (BIRD et al., 2000; TAYLOR et al., 2000; FRICKE y WOLFF, 2002), la digitalización vectorial en pantalla teniendo en cuenta la leyenda previamente establecida.

En la construcción de la cartografía, expresión sintética de la información que se recoge, el diseño de una leyenda que transmita la máxima información posible es fundamental. Tradicionalmente, la estructuración de una leyenda de usos y coberturas del suelo ha dependido, además de la naturaleza de las fuentes de información, de los objetivos (medioambientales, planificación de usos del territorio, etc.) para los cuales se necesitaba la elaboración de esa cartografía. La leyenda cartográfica aplicada en el municipio de Valencia está basada en la estructura aportada por el proyecto CORINE Land Cover (EEA, 2007), organizándose en 3 niveles jerárquicos en los que las 
Figura 2: Esquema del procedimiento metodológico.

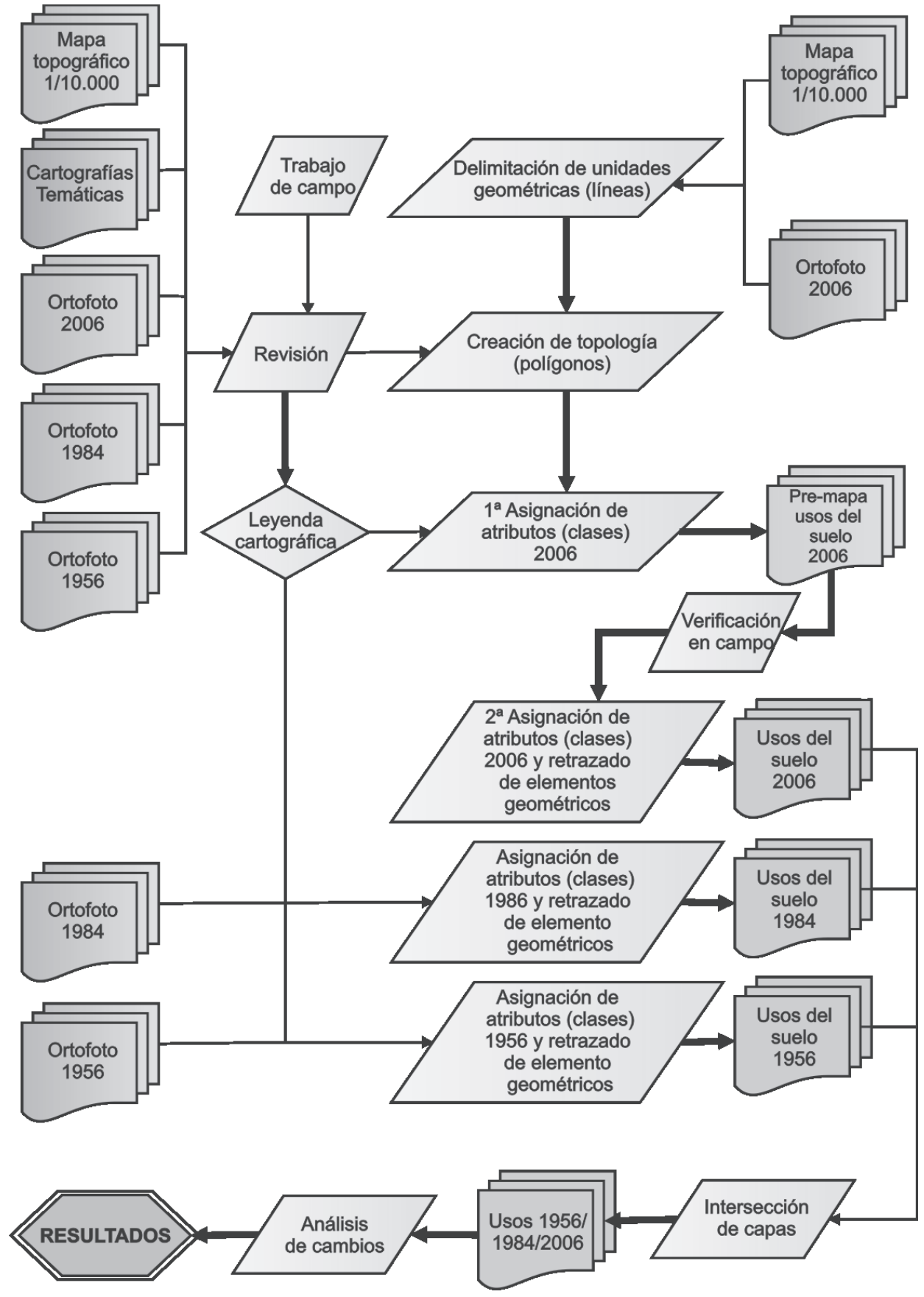

Fuente: Elaboración propia 
cuatro clases principales a nivel 1 se van subdividiendo en 13 y 33 clases a nivel 2 y 3 , respectivamente.

La extracción de la información se efectuó en dos niveles. En primer lugar, se construyó la base de datos geométricos, proceso de digitalización vectorial, teniendo en cuenta las clases de usos/coberturas del suelo. Con este fin, se digitalizaron en pantalla los elementos espaciales identificables en las ortofotos más recientes (2006). En segundo lugar, se construyeron las tablas de bases de datos asociadas, asignándose los identificadores de las clases de leyenda a los polígonos digitalizados.

Las cartografías para las fechas anteriores se realizaron progresivamente mediante la adición, sustracción de elementos o modificación de atributos de la capa correspondiente a la fecha inmediatamente posterior disponible. Este procedimiento permite optimizar la coherencia interna entre las distintas capas, minimizando en lo posible desplazamientos irreales en las cartografías que puedan ser contabilizados en el análisis como falsos cambios (PERDIGAO y ANONNI, 1997). La información obtenida fue revisada y corregida, tanto en gabinete, como mediante visitas de campo. Por medio de cruce de tablas o matrices de confusión, y utilizando el sumatorio de la superficie calculada para los polígonos intersectados, se obtuvieron los datos de cambios de usos entre los distintos periodos considerados. El análisis permite responder, así, a cuatro preguntas clave: qué, cuánto, cuándo y dónde. Esta información resulta de gran relevancia para las posibles interpretaciones del fenómeno.

Para caracterizar la dinámica espacio-temporal de cambio de los usos/coberturas del suelo, resulta fundamental la construcción de un sistema de indicadores que aporten información sintética de las tendencias de cambio. En este trabajo se han seleccionado 20 indicadores agrupados en 6 áreas temáticas. Se presentan aquí los resultados de 10 de ellos, los referidos principalmente al sellado antropogénico del suelo. El esquema está basado en los aplicados en 15 áreas urbanas europeas durante la realización del proyecto MOLAND (KASANKO et al., 2006). Más allá de algunas modificaciones puntuales en el proceso de cálculo, en este trabajo se han añadido otros indicadores que profundizan en el análisis. La tabla 1 recoge la definición, procedimiento de cálculo y fuente utilizada para la elaboración de los indicadores.

\section{RESULTADOS Y DISCUSIÓN}

El análisis de la evolución de las superficies artificiales y la aplicación de los indicadores dejan patente que, dentro de la dinámica general de cambio de usos y coberturas del suelo producidos en Valencia entre 1956 y 2006, la transformación fundamental ha consistido en un importante proceso de urbanización (Tabla 2). El papel de Valencia como centro de servicios y foco de industrialización la convierte en la principal receptora del flujo inmigratorio en toda la provincia. El crecimiento demográfico (CP) durante todo el periodo es del 58,94\%, siendo el principal motor de las transformaciones experimentadas (Figura 3). Mientras, el crecimiento de la superficie construida (CSC) representa un $118,47 \%$, con un ritmo medio anual de construcción (ASC) de 47,55 ha/año. 
Figura 3: Evolución de la población (1900-2009) en el municipio de Valencia.

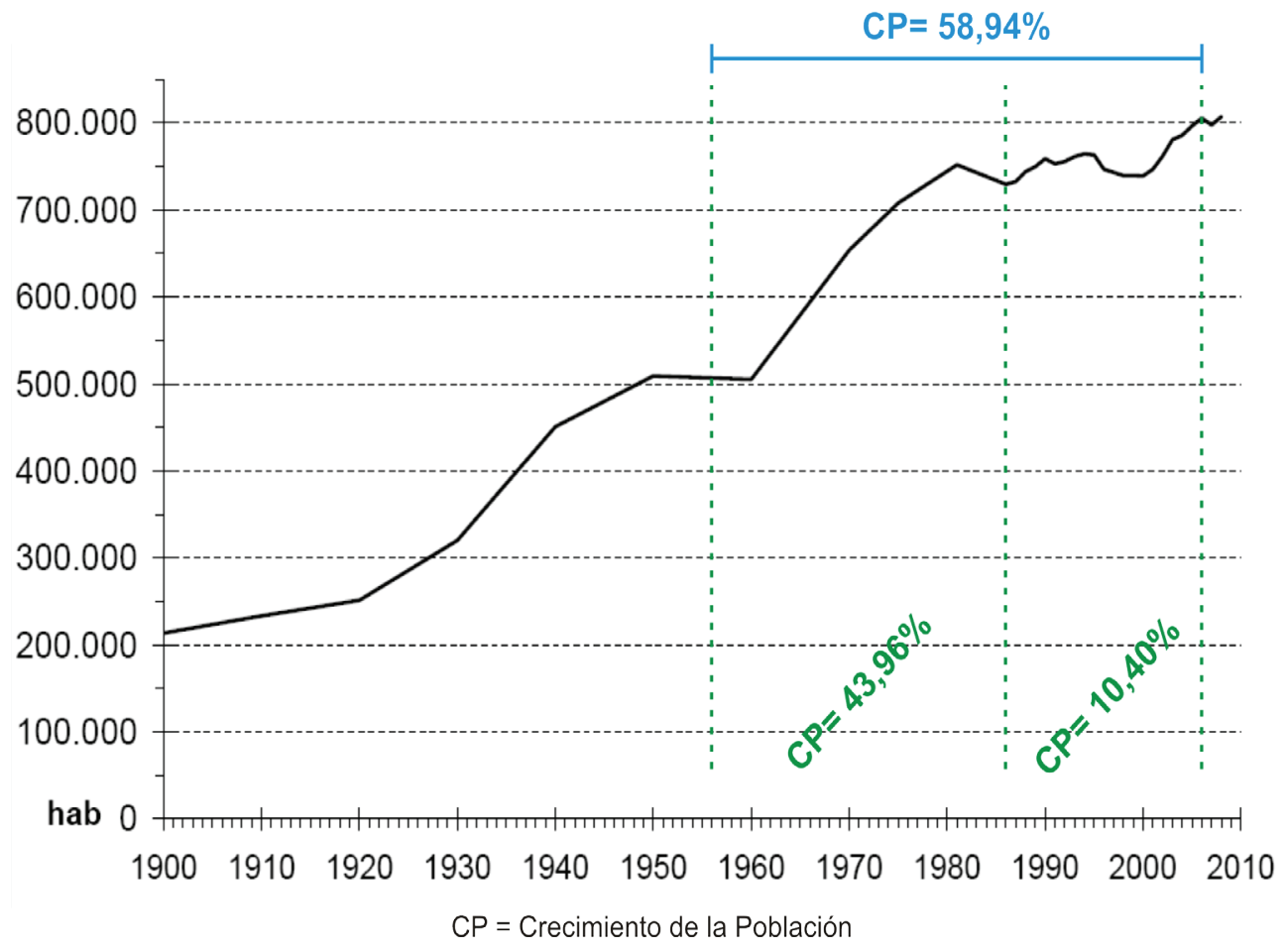

Fuente: Instituto Valenciano de Estadística

El modelo de expansión, a diferencia del observado en la mayoría de los municipios metropolitanos alicantinos (VALERA et al., 2007b), es de alta densidad edificatoria (Figura 4). En 1956, la superficie construida (SC) representaba 2.007 ha. En cifras relativas, el porcentaje de superficie construida (PSC) en esas mismas fechas correspondía al $14,95 \%$. Son éstos unos valores relativamente altos que se relacionan con la centralidad y capitalidad de la ciudad de Valencia a nivel metropolitano y regional. Por lo que respecta a la densidad de las zonas urbanas, el porcentaje de zonas de alta densidad (PAD) era significativamente predominante, con un $86,08 \%$, al de las de baja densidad (PBD), que era de 13,92\%. Una característica particular de la ciudad de Valencia es la estrecha relación simbiótica con el espacio agrícola que la rodea y la ha sostenido durante siglos. Es quizá esa valoración de la actividad agrícola intensiva una de las principales causas del tradicional carácter denso y concentrado de la ciudad de Valencia en contraposición con otras áreas urbanas. Así, la superficie construida por habitante (SCP) era relativamente baja, con 39,61 $\mathrm{m}^{2} /$ hab. La dinámica demográfica a lo largo de la segunda mitad del siglo XX y, especialmente, a partir de los años sesenta, junto a las profundas transformaciones socioeconómicas que se han venido desarrollando en esos mismos años, pueden 
Figura 4: Ejemplo de expansión urbana (1956-2006) en el sector suroriental de la ciudad de Valencia..

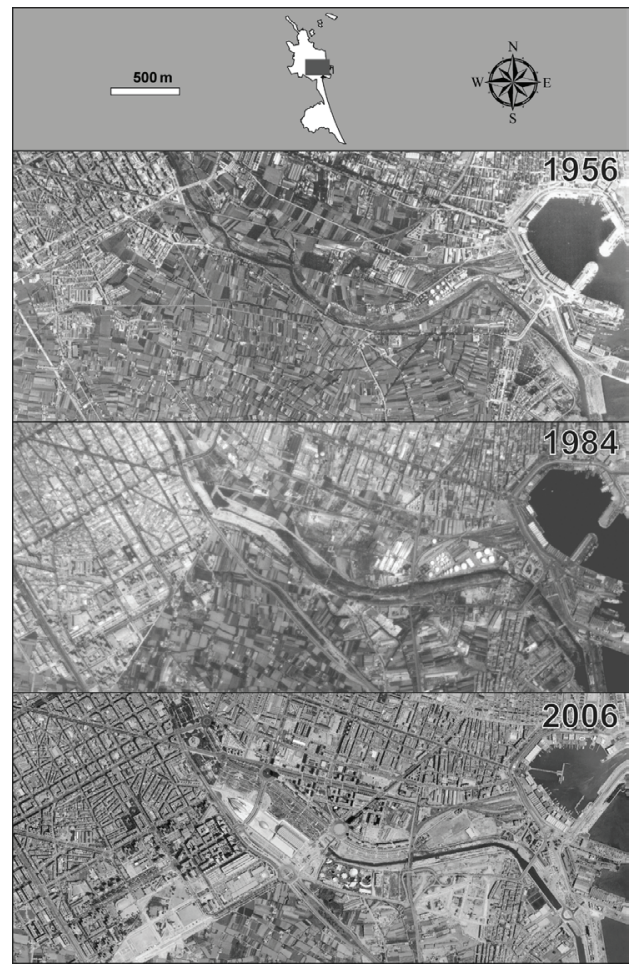

Fuente: Elaboración propia

considerarse los principales factores explicativos de los cambios en los usos del suelo. Junto a estas transformaciones socioeconómicas se ha producido un cambio de comportamiento en lo que se refiere a la utilización del territorio.

La riada de 1957 modifica la dinámica urbana ya que incorpora más cantidad de suelo al mercado inmobiliario, trastocando las directrices del Plan General de Ordenación Urbana de 1946 que proponía un modelo de crecimiento radioconcéntrico dirigido hacia las zonas de secano y conservando, en la medida de lo posible, las áreas con dedicación agrícola intensiva. Entre 1956 y 1984 el crecimiento demográfico (CP) fue del 43,96\%. En ese mismo periodo, el crecimiento de la superficie construida (CSC) fue del 75,68\%, con un ritmo medio anual (ASC) de 54,24 ha/año. La expansión se localiza principalmente en torno al núcleo urbano de Valencia, siguiendo primero un modelo en "estrella" sobre los principales ejes de comunicación, para más tarde adoptar un crecimiento "en mancha de aceite" en el que las áreas urbanas preexistentes han tendido a la coalescencia y compactación (Figura 5). Otros focos secundarios se centran en las pedanías circundantes y en la pequeña área de turismo litoral en el extremo sureste. Así, en 1984 las superficies construidas (SC) alcanzaban las 3.526 ha, con un porcentaje (PSC) del 26,27\%, y se 
Figura 5: Dinámica espacio-temporal (1956-2006) del crecimiento urbano en el municipio de Valencia

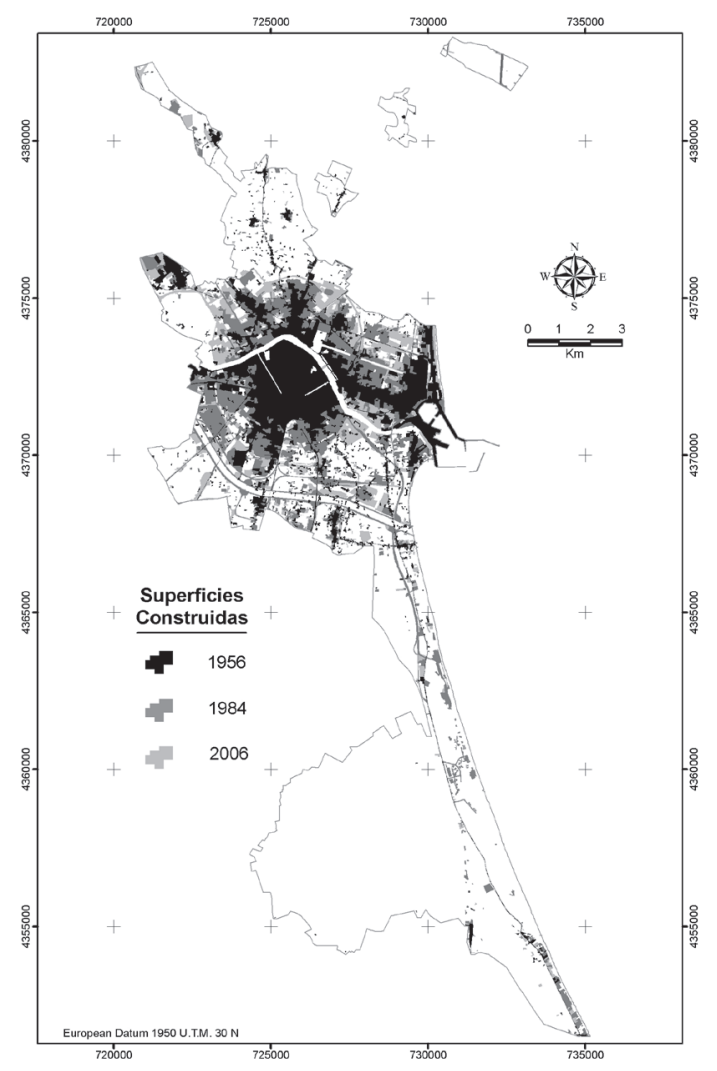

Fuente: Elaboración propia

habían incrementado, por tanto, de forma considerable. La densidad de edificación de las zonas urbanas era superior a la de la fecha antecedente. Así, el porcentaje de zonas de alta densidad (PAD) representaba el 90,09\% frente al 9,91\% de zonas de baja densidad (PBD). La superficie construida disponible por persona (SCP) se incrementó hasta $48,34 \mathrm{~m}^{2} / \mathrm{hab}$. y revela una utilización urbana del suelo algo más extensiva por parte de la población municipal.

En el periodo 1984-2006 el crecimiento de la superficie construida (CSC) es del $24,36 \%$, con un ritmo medio anual (ASC) de 39,03 ha/año. Hay que tener en cuenta que el crecimiento de la población $(\mathrm{CP})$ es considerablemente inferior al periodo anterior (marcado por la etapa desarrollista) y representa $10,40 \%$. Continúa, no obstante, la tendencia de ocupación de espacios intraurbanos, conformando una ciudad cerrada con una delimitación bien definida (Figura 5). Así, en 2006, última fecha analizada, la superficie construida (SC) es de 4.385 ha, un porcentaje (PSC) respecto a la superficie municipal de 32,67\%. La densidad de edificación se ha incrementado respecto a 1984 pues representa, respectivamente, un 91,17\% para las áreas de alta densidad (PAD) 
y un $8,83 \%$ para las de baja (PBD). Además, el requerimiento de espacio urbano por habitante también es cada vez mayor, de forma que la superficie construida por persona (SCP), aunque relativamente baja en comparación con otras áreas urbanas, se ha incrementado hasta los $54,45 \mathrm{~m}^{2} / \mathrm{hab}$.

Buena parte de la superficie sellada antropogénicamente corresponde a Fluvisoles calcáricos (RUBIO et al., 1996); suelos que, de acuerdo con ANTOLÍN y AÑÓ (1998), presentan elevada o muy elevada capacidad de uso al tener unas propiedades, tanto intrínsecas como extrínsecas, idóneas para el uso agrícola (Figura 6). Los procesos de erosión hídrica son inexistentes o muy ligeros. El espesor efectivo del medio edáfico supera los $80 \mathrm{~cm}$., proporcionando un medio adecuado para el desarrollo radicular, la retención del agua disponible y el suministro de los nutrientes existentes. No existen afloramientos rocosos y el porcentaje de pedregosidad no dificulta el laboreo ni afecta al uso de maquinaria agrícola. No hay salinidad o ésta es muy baja, siempre inferior a $2 \mathrm{dS} / \mathrm{m}$. Son suelos de $\mathrm{pH}$ básico, carbonatados y que están bien drenados, de este modo los cultivos no presentan problemas por encharcamiento. En relación con las características físicas y químicas del edafosistema éstas son favorables: la textura es equilibrada, la estructura adecuada, la porosidad y la retención de agua son idóneas, el contenido de nutrientes es equilibrado (en la proporción necesaria para el desarrollo vegetal) y existe una respuesta aceptable al uso de fertilizantes. Únicamente pueden presentar limitaciones menores susceptibles de mejora como, por ejemplo, materia orgánica deficitaria Además la pendiente es llana, las condiciones térmicas son

Figura 6: . Capacidad de uso de los suelos en el área metropolitana de Valencia.

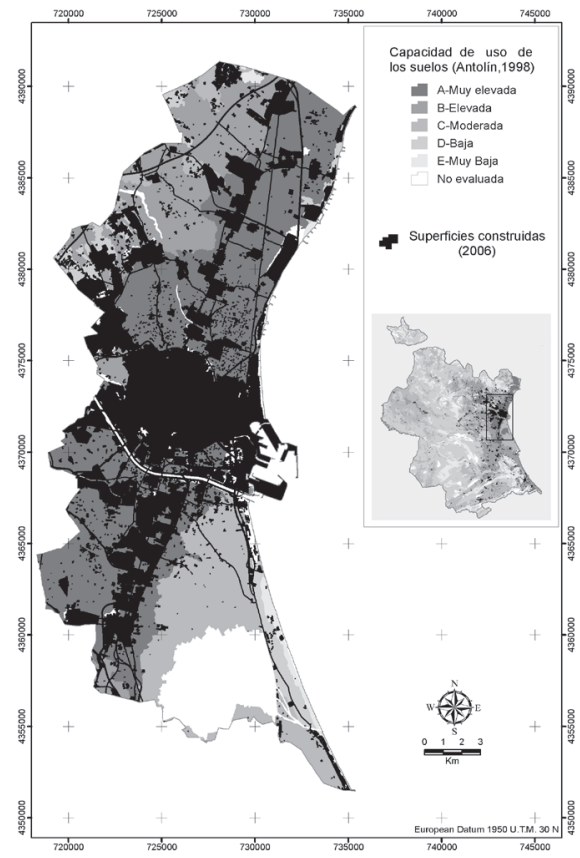

Fuente: Elaboración propia a partir de Antolín (1998) 
adecuadas y la disponibilidad hídrica es alta. Por tanto, la ausencia de limitaciones permite la implantación de un gran número de cultivos de excelente productividad.

Durante el periodo 1984-2006 se destruyeron 470 ha de suelos con elevada y muy elevada capacidad de uso (CAB), cifra que representa un porcentaje (PCAB) del $15,40 \%$ respecto a 1984 . Estos datos resultan especialmente significativos si se considera que el porcentaje de superficie protegida (PROT) en 2007 es del 43,43\%, área que corresponde, en su mayor parte, al Parque Natural de l'Albufera. Por tanto, en caso de continuar el proceso de sellado antropogénico, una vez superada la crisis económica actual que ha ralentizado o detenido muchos de los macroproyectos de urbanización, lo hará sobre suelos con elevada y muy elevada capacidad de uso. Así, si en el cálculo de algunos indicadores se considerase como superficie de referencia únicamente la no afectada por ninguna figura de protección (7.593 ha), los valores se incrementarían de forma significativa. En ese escenario, por ejemplo, el porcentaje de superficie construida (PSC) en 2006 representaría el 54,14\% del total municipal.

\section{CONCLUSIONES}

Valencia ha experimentado, durante el periodo estudiado, la implantación de nuevos espacios residenciales, industriales, comerciales y de servicios ligados al centro de un área metropolitana de más de 1,5 millones de habitantes en 2009 . La superficie urbana se ha incrementado entre 1956 y 2006 de 2.007 ha $(14,95 \%$ del municipio) a 4.385 ha $(32,67 \%)$, con un remarcable incremento del ritmo de crecimiento en los últimos años. Se enmarca así, al igual que otros municipios del litoral mediterráneo español como, entre otros, Elx (VALERA et al., 2006), en un proceso acelerado de degradación e incluso destrucción de un porcentaje significativo de los mejores suelos agrícolas.

En este marco territorial, especialmente frágil y vulnerable, el edafosistema constituye un componente fundamental. El suelo, recurso natural no renovable en una escala de tiempo humano en función de una tasa de formación muy lenta, es un sistema multifuncional: produce biomasa; protege a organismos y microorganismos que viven exclusivamente en su interior; aporta el soporte físico de las actividades antropogénicas; es fuente de materias primas; participa en el ciclo bioquímico, geoquímico e hidrológico; filtra, neutraliza y transforma sustancias contaminantes, etc. Por tanto, una utilización acertada del mismo es una premisa fundamental para conseguir un desarrollo sostenible, sobre todo si consideramos que todas las actividades antrópicas que fomentan la ocupación del territorio, particularmente en áreas tan dinámicas como Valencia, pueden provocar la eliminación definitiva o la pérdida prácticamente irrecuperable del recurso edáfico, convertido en mero soporte de las actividades relacionadas con la urbanización o la implantación de infraestructuras viarias y equipamientos, perdiendo el suelo su carácter multifuncional. 
Tabla 1. Sistema de indicadores: definición, forma de cálculo y fuentes de información

\begin{tabular}{|c|c|}
\hline Indicador & Definición \\
\hline $\begin{array}{c}\text { Superficie } \\
\text { Construida (SC) }\end{array}$ & $\begin{array}{l}\text { Superficie total ocupada por las áreas } \\
\text { construidas, en bectareas. Indica la dimensión } \\
\text { espacial absoluta del sellado artificial del } \\
\text { suelo en una fecha determinada. }\end{array}$ \\
\hline $\begin{array}{l}\text { Porcentaje de } \\
\text { Superficie } \\
\text { Construida (PSC) }\end{array}$ & $\begin{array}{l}\text { Porcentaje de superficie construida respecto a } \\
\text { la superficie total. Indica la dimensión espacial } \\
\text { relativa del sellado artificial del suelo en una } \\
\text { fecha determinada. }\end{array}$ \\
\hline $\begin{array}{c}\text { Porcentaje de } \\
\text { Zonas Urbanas de } \\
\text { Alta Densidad } \\
\text { (PAD) }\end{array}$ & $\begin{array}{l}\text { Porcentaje de zonas urbanas de alta densidad } \\
\text { ( } 80 \% \text { de edificaciones) respecto a la } \\
\text { superficie total. Indica una elevada densidad } \\
\text { de edificación. }\end{array}$ \\
\hline $\begin{array}{c}\text { Porcentaje de } \\
\text { Zonas Urbanas de } \\
\text { Baja Densidad } \\
\text { (PBD) }\end{array}$ & $\begin{array}{l}\text { Porcentaje de zonas urbanas de baja densidad } \\
(<20 \% \text { de edificaciones) respecto a la } \\
\text { superficie total. Indica una baja densidad de } \\
\text { edificación. }\end{array}$ \\
\hline $\begin{array}{l}\text { Crecimiento de las } \\
\text { Superficies } \\
\text { Construidas (CSC) }\end{array}$ & $\begin{array}{l}\text { Crecimiento total de la superficie construida } \\
\text { durante el periodo considerado. Expresa la } \\
\text { magnitud porcentual del cambio entre las dos } \\
\text { fechas analizadas. }\end{array}$ \\
\hline $\begin{array}{l}\text { Crecimiento Anual } \\
\text { de las Superficies } \\
\text { Construidas (ASC) }\end{array}$ & $\begin{array}{l}\text { Rátio entre el crecimiento total de la superficie } \\
\text { construida durante el periodo considerado y el } \\
\mathrm{n}^{\circ} \text { de aṽos transcurridos. Indica el ritmo anual } \\
\text { estimado del proceso. }\end{array}$ \\
\hline $\begin{array}{l}\text { Crecimiento de la } \\
\text { Población (CP) }\end{array}$ & $\begin{array}{l}\text { Cambio en la población del área de estudio } \\
\text { entre dos fechas, en porcentaje. Indica la } \\
\text { variación de la presión antrópica directa sobre } \\
\text { el conjumto del territorio. }\end{array}$ \\
\hline $\begin{array}{l}\text { Superficie } \\
\text { Construida } \\
\text { disponible por } \\
\text { Persona (SCP) }\end{array}$ & $\begin{array}{l}\text { Superficie construida disponible por habitante, } \\
\text { en } \mathrm{m}^{2} \text { por persona. Indica la media de } \\
\text { ocupacion del territorio para usos urbanos por } \\
\text { habitante. }\end{array}$ \\
\hline $\begin{array}{l}\text { Pérdida de suelos } \\
\text { con Elevada y Muy } \\
\text { Elevada Capacidad } \\
\text { de Uso (CAB) }\end{array}$ & $\begin{array}{l}\text { Superficie construida sobre suelos con } \\
\text { capacidad de uso muy elevada o elevada } \\
\text { (clases A y B). Indica la magnitud absoluta de } \\
\text { la pérdida de los mejores suelos agricolas. }\end{array}$ \\
\hline $\begin{array}{c}\text { Porcentaje de } \\
\text { Pérdida de suelos } \\
\text { con Elevada y Muy } \\
\text { Elevada Capacidad } \\
\text { de Uso (PCAB) }\end{array}$ & $\begin{array}{l}\text { Superficie construida sobre suelos con } \\
\text { capacidad de uso muy elevada o elevada } \\
\text { (clases A y B) respecto a la superficie total de } \\
\text { esa misma clase de capacidad de uso en la } \\
\text { fecha inicial Indica la magnitud relativa, en } \\
\% \text {, de la pérdida de los mejores suelos } \\
\text { agricolas. }\end{array}$ \\
\hline
\end{tabular}

Porcentaje de Porcentaje de superficie con alguna figura de Superficie protección (propuesta o aprobada) respecto a Protegida (PROT) la superficie total del área de estudio. Indica la calidad para la conservación del territorio.

\section{Cálculo}

Total de superficie construida, inchyendo las zonas urbanas de alta y baja densidad. Fuente: (1).

$P S C=(S C / S T) \times 100$

Siendo $S C$ el total de superficie construida, y $S T$ la superficie total. Fuente: (1).

$$
P A D=(S C A / S C) \times 100
$$

Siendo SCA el total de superficie urbana de alta densidad, y $S C$ la superficie construida total Fuente: (1).

$P B D=(S C B / S C) \times 100$

Siendo $S C B$ el total de superficie urbana de baja densidad, y $S C$ la superficie construida total Fuente: (1).

$\left.\operatorname{CSC}=\left(\left(S C_{r}-S C_{\vartheta}\right) / S C_{\phi}\right)\right) \times 100$

Siendo $S C_{l}$ la superficie construida en la fecha

final y $S C_{0}$ la superficie construida inicial. Fuente: (1).

$$
A S C=\left(S C_{r}-S C_{V}\right) / t
$$

Siendo $S C_{i}$ la superficie en ha construida en la fecha más actual, $S C_{b}$ la superficie construida en la fecha inicial, y $t$ el $n^{\circ}$ de años transcurridos. Fuente: (1)

$$
\left.C P=\left(\left(P_{r}-P_{a}\right) / P_{Q}\right)\right) \times 100
$$

Siendo $P_{f}$ el n ${ }^{\circ}$ de habitantes en la fecha más actual y $P_{0}$ en la fecha inicial. Fuente: 2 .

$$
S C P=S C / P
$$

Donde $S C$ es el total de superficie construida $\left(\right.$ en $\mathrm{m}^{2}$ ) en la fecha considerada y $P$ el número de habitantes. Fuente: (1) y (2).

Total de la superficie construida sobre suelos con capacidad de uso de clase A y B, en ha. Fuente: (1) y (3).

$\left(C A B_{l} / S A B_{2}\right) \times 100$

Siendo $C A B$, la superficie construida sobre suelos clase $A$ y B de capacidad de uso y $S A B_{0}$ ha superficie total con capacidad de uso A y B en la fecha inicial. Fuente: (1) y (3).

\section{PROT $=(P R T / S T) \times 100$}

Siendo $P R T$ la superficie protegida y $S T$ la superficie del área de estadio. Las figuras de protección consideradas son: Parques Naturales, Lugares de Interés Comunitario, Zonas de especial protección para las aves, Paisajes protegidos y Parajes municipales. Fuente: (4).

Fuentes: 1) Cartografia de uso/coberturas de elaboración propia.

2) Instituto Nacional de Estadistica (INE). Instituto Valenciano de Estadistica (IVE).

3) Cartografia de capacidad de uso de los suelos en la Comunidad Valenciana (Antolin, 1998).

4) Consellería de Medi Ambient, Territori i habitatge. Europarc (www. europarc-es.org).

Fuente: Elaboración propia 
Tabla 2. Resultados de los indicadores aplicados en el municipio de Valencia

\begin{tabular}{|c|c|c|c|c|}
\hline Indicador & 1956 & 1984 & 2006 & \\
\hline 1.1. Superficie Construida (SC) & 2.007 & 3.526 & 4.385 & ha \\
\hline 1.2. Porcentaje de Superficie Construida (PSC) & 14,95 & 26,27 & 32,67 & $\%$ \\
\hline \multicolumn{5}{|l|}{$\begin{array}{l}\text { 1.7. Porcentaje de Zonas Urbanas de Alta y Baja } \\
\text { Densidad (PAD, PBD) }\end{array}$} \\
\hline + Porcentaje de zonas de alta densidad (PAD) & 86,08 & 90,09 & 91,17 & $\%$ \\
\hline + Porcentaje de zonas de baja densidad (PBD) & 13,92 & 9,91 & 8,83 & $\%$ \\
\hline \multirow[t]{2}{*}{$\begin{array}{l}\text { 5.2. Superficie Construida disponible por Persona } \\
\text { (SCP) }\end{array}$} & 39,61 & 48,34 & 54,45 & $\mathrm{~m}^{2} / \mathrm{hab}$ \\
\hline & $1956-2006$ & $1956-1984$ & 1984-2006 & \\
\hline $\begin{array}{l}\text { 1.3. Crecimiento total de la Superficie Construida } \\
\text { (CSC) }\end{array}$ & 118,47 & 75,68 & 24,36 & $\%$ \\
\hline $\begin{array}{l}\text { 1.4. Crecimiento anual de la Superficie Construida } \\
\text { (ASC) }\end{array}$ & 47,55 & 54,24 & 39,03 & ha/aĩo \\
\hline \multirow[t]{2}{*}{ 4.2. Crecimiento de la Población (CP) } & 58,94 & 43,96 & 10,40 & $\%$ \\
\hline & & & $1984-2005$ & \\
\hline \multicolumn{3}{|c|}{ 2.3. Pérdida de Suelos con Elevada y Muy Elevada Capacidad de Uso (CAB) } & 470 & ha \\
\hline \multirow{2}{*}{\multicolumn{3}{|c|}{$\begin{array}{l}\text { 2.4. Porcentaje de Pérdida de Suelos con Elevada y Muy Elevada Capacidad de } \\
\text { Uso (PCAB) }\end{array}$}} & 15,40 & $\%$ \\
\hline & & & 2007 & \\
\hline \multicolumn{3}{|l|}{ 6.1. Porcentaje de Superficie Protegida (PROT) } & 43,43 & $\%$ \\
\hline
\end{tabular}

Fuente: Elaboración propia

\section{BIBLIOGRAFÍA}

ACOSTA, J.A.; FAZ, A. y MARTÍNEZ-MARTÍNEZ, S. (2007): “Crecimiento urbano e industrial en la ciudad de Murcia y alrededores entre 1956 y 1999: cambios en los usos del suelo", en: Bellinfante, N., Jordán, A. (eds.): Tendencias Actuales de la Ciencia del Suelo,. Universidad de Sevilla, Sevilla, pp. 895-901.

ANTOLIN, C. (Coord.) (1998): El Suelo como Recurso Natural en la Comunidad Valenciana, Consellería de Obras Públicas, Urbanismo y Transportes. Generalitat Valenciana, Valencia. 
ANTOLÍN, C. y AÑÓ, C. (1998): “Capacidad de uso de los suelos de la Comunidad Valenciana“", en: El suelo como Recurso Natural en la Comunidad Valenciana. Consellería de Obras Públicas, Urbanismo y Transportes. Generalitat Valenciana, Valencia, pp. 111-131.

BIRD, A.C.; TAYLOR, J.C. y BREWER, T.R. (2000): "Mapping National Park landscape from ground, air and space", en: International Journal of Remote Sensing, 23 (13-14), pp. 2719-2736.

CEC (2002): Communication from the Commission to the Council, the European Parliament, the Economic and Social Committee and the Committee of the Regions. Towards a Thematic Strategy for Soil Protection, Commission of the European Communities, Brussels.

EEA (2002): Proceedings of the Technical Workshop on Indicators for Soil Sealing, Technical Report 80, European Environment Agency, Copenhagen.

EEA (2006a): Land accounts for Europe 1990-2000. Towards integrated land and ecosystems accounting, EEA Report 11/2006, European Environment Agency, Copenhagen.

EEA (2006b): Urban sprawl in Europe. The ignored challenge, EEA Report 10, European Environment Agency, Copenhagen.

EEA (2007): CLC2006 Technical Guidelines, Technical Report 17, European Environment Agency, Copenhagen.

FRICKE, R. y WOLFF, E. (2002): “The MURBANDY Project: development of land use and network databases for the Brussels area (Belgium) using remote sensing and aerial photography", en: International Journal of Applied Earth Observation and Geoinformation, 4 (1), pp. 33-50.

KASANKO, M.; BARREDO, J.I.; LAVALLE, C.; MCCORMICK, N.; DEMICHELI, L.; SAGRIS, V. y BREZGER, A. (2006): "Are European cities becoming dispersed?. A comparative analysis of 15 European urban areas", en: Landscape and urban planning, 77, pp. 111-130.

MARM. (2009): Escenario de los usos del territorio en Europa: análisis cualitativo y cuantitativo, Ministerio de Medio Ambiente y Medio Rural y Marino, Madrid.

NUISSL, H.; HAASE, D.; LANZENDORF, M. y WITTMER, H. (2009): "Environmental impact assessment of urban land use transitions - A contextsensitive approach", en: Land Use Policy, 26, pp. 414-424.

OJEDA, J. y VILLAR, A. (2006): "Evolución del suelo urbano/alterado en el litoral de Andalucía (España): 1998-2002”, en: Geofocus, 7, pp. 73-99.

PERDIGAO, V. y ANONNI, A. (1997): Technical and methodological guide for updating CORINE land cover database, European Commission, BrusselsLuxembourg. 
RUBIO, J.L.; SÁNCHEZ, J. y FORTEZA, J. (1996): Proyecto LUCDEME. Mapa de suelos de la Comunidad Valenciana. Valencia (722), Consellería de Agricultura, Generalitat Valenciana, Valencia.

SANCHEZ-ESPESO, J.M. (2000): "Análisis del proceso de rectificación de una imagen aérea de eje vertical para obtener una ortoimagen digital”, en: Mapping, 64, pp. 20-32.

SCALENGHE, R. y AJMONE MARSAN, F. (2009): "The anthropogenic sealing of soils in urban areas", en: Landscape and Urban Planning, 90, pp. 1-10.

SERRANO, A. (2005): "La problemática supramunicipal del modelo territorial del siglo XXI: áreas metropolitanas y regiones funcionales urbanas", en: Territorio y Desarrollo Local, Marzo 2005, pp. 11-16.

TAYLOR, J.C.; BREWER, T.R. y BIRD, A.C. (2000): "Monitoring landscape change in the National Parks of England and Wales using aerial photo interpretation", en: International Journal of Remote Sensing, 21 (13-14), pp. 2737-2752.

TREITZ, J.C. y ROGAN, J. (2004): "Remote sensing for mapping and monitoring land-cover and land-use change - an introduction", en: Progress in Planning, 61 (4), pp. 269-279.

VALERA, A.; AÑÓ, C. y SÁNCHEZ, J. (2006): "Urban growth (1956-2005) and soil degradation. The case of Elche, Spain", en: Proceedings of the International ESSC Conference on "Soil and Water Conservation under Changing Land Use", Universitat de Lleida, Lleida, pp. 101-104.

VALERA, A.; AÑÓ, C. y SÁNCHEZ, J. (2007a): "Pérdida de suelo y crecimiento urbano (1956-1998) en el Área Metropolitana de Valencia", en: Bellinfante, N. y Jordán, A. (eds.): Tendencias Actuales de la Ciencia del Suelo, Universidad de Sevilla, Sevilla, pp. 915-921.

VALERA, A.; AÑÓ, C. y SÁNCHEZ, J. (2007b): "Urban growth (1956-1998) in the metropolitan area of Alacant-Elx (Comunitat Valenciana)", en: Boletín de la AGE, 44, pp. 169-186. 